\title{
PENGEMBANGAN PERANGKAT PEMBELAJARAN TEAM BASED LEARNING- PROBLEM SOLVING BERBANTUAN WHATSAPP DAN ZOOM MEETING PADA PEMBELAJARAN DARING
}

\author{
Asri Arbie ${ }^{1}$, Puput Salsabna F. Satri'1), Dewa Gede Eka Setiawan"1), Abd. Wahidin Nuayi1) \\ Trisnawaty Junus Buhungo')
}

\author{
1)Program Studi Pendidikan Fisika, Universitas Negeri Gorontalo, Gorontalo, Sulawesi Utara, Indonesia \\ Corresponding author : Puput Salsabina F. Satri \\ E-mail : puputsalsabinasatri@gmail.com
}

Diterima 31 Oktober 2021, Direvisi 05 November 2021, Disetujui 05 November 2021

\begin{abstract}
ABSTRAK
Penelitian ini merupakan penelitian pengembangan perangkat pembelajaran yang bertujuan untuk menghasilkan perangkat pembelajaran yang berkualitas. Rumusan masalah penelitian ini adalah bagaimana kualitas perangkat pembelajaran yang dikembangkan dengan model pembelajaran Team Based Learning. Perangkat pembelajaran ini dikembangan dengan menggunakan model pengembangan Plomp. Teknik pengumpulan data yaitu dengan validitas melalui validasi perangkat, kepraktisan melalui observasi keterlaksanaan, angket respon guru dan peserta peserta didik. Dari penelitian ini diperoleh hasil: (1) perangkat yang dikembangkan valid melalui uji validitas konstruk dengan rata-rata persentase validitas untuk silabus sebesar $98,33 \%$ dengan kategori valid, RPP sebesar $78,48 \%$ termasuk kategori valid dengan revisi kecil, bahan ajar sebesar 79,68\% termasuk kategori valid dengan revisi kecil, dan LKPD sebesar 76,04\% yang termasuk dalam kategori valid dengan revisi kecil; (2) perangkat yang dikembangkan praktis ditunjukkan oleh rata-rata presentase keterlaksanaan pembelajaran sebesar 92,26\% kategori sangat baik, kemudian respon guru terhadap perangkat pembelajaran yang dikembangkan sebesar $99,39 \%$ kategori sangat baik serta respon peserta didik terhadap proses pembelajaran menggunakan perangkat yang dikembangkan sebesar $82,66 \%$ kategori baik.
\end{abstract}

Kata kunci: Perangkat pembelajaran; Team Based Learning; Problem Solving; Plomp.

\begin{abstract}
This research is research and development of learning tools that aim to produce quality learning tools. The formulation of the research problem is how the quality of learning tools developed with the TeamBased Learning learning model is. This learning device was developed using the Plomp development model. Data collection techniques are valid through device validation, practicality through implementation observation, teacher and student response questionnaires. From this study obtained results: (1) devices developed valid through construct validity tests with an average percentage validity for syllabus of $98.33 \%$ with valid categories, RPP of $78.48 \%$ including valid categories with small revisions, teaching materials of $79.68 \%$ including valid categories with minor revisions, and LKPD of $76.04 \%$ which fall into valid categories with minor revisions; (2) devices developed practically indicated by an average percentage of learning implementation of $92.26 \%$ excellent category, then teacher response to learning devices developed by $99.39 \%$ excellent category and learners' response to the learning process using developed devices by $82.66 \%$ good category.
\end{abstract}

Keywords: Learning tools; Team-Based Learning; Problem Solving; Plomp.

\section{PENDAHULUAN}

Hobri (2010:31) perangkat pembelajaran merupakan sekumpulan sumber belajar yang memungkinkan guru dan peserta didik dalam melakukan kegiatan pembelajaran. Menurut Ibrahim (Trianto, 2008:121) yang menyatakan bahwa perangkat pembelajaran adalah alat atau perlengkapan yang memungkinkan peserta didik dan guru melaksanakan pembelajaran. Sehingga dapat ditarik kesimpulan bahwa perangkat pembelajaran ialah sekumpulan sumber belajar atau alat/perlengkapan yang memungkinkan peserta didik dan guru dalam melakukan proses belajar mengajar. Adapun komponen perangkat pembelajaran antara lain: silabus, Rencana Pelaksanaan Pembelajaran, bhan ajar, Lembar Kerja Peserta Didik, instrumen penilaian, dan media pembelajaran (Trianto, 2008:121). 
Michaelsen dan Sweet (2008) Team Based Learning adalah pembelajaran dengan menggabungkan pembelajaran kelompok kecil dan kelompok besar dengan menggabungkan kelompok kecil ke dalam pengaturan kelompok besar. Menurut Vries (2021:2) team based learning merupakan model pengajaran baru yang dapat pembelajaran kelompok kecil ke tingkat efektivitas baru dimana TBL mengalihkan focus guru sebagai penyampai pengetahuan menjadi fasilitator pembelajaran. Sehingga dapat disimpulkan bahwa team based learning adalah model pengajaran yang mendorong pembelajaran tidak hanya dengan berpartisipasi aktif dalam pengembangan dan pemahaman konsep, tetapi juga dengan peserta didik aktif berpartisipasi dalam pemecahan masalah dan pengembangan keterampilan dalam kegiatan kelompok dengan populasi yang beragam.

Menurut Michaelsen dan Sweet (2008:7) tujuan utama dalam TBL yaitu untuk membuat peserta didik tidak hanya sekedar focus pada konseptual namun peserta didik juga memiliki kesempatan untuk berlatih menggunakan konsept untuk menyelesaikan permasalahan. Sejalan dengan tujuan utama dari team based learning menurut Levine dkk, 2004; Chung dkk, 2009 (Vries 2021:4) dalam pembelajaran menggunakan team based learning peserta didik belajar bagaimana bekerja secara kolaboratif dalam kelompok guna memecahkan permasalahan otentik.

Menurut Michaelsen dan Sweet (2008:8) terdapat empat elemen penting yang perlu diperhatikan agar Team Based Learning dapat berhasil diterapkan, yakni:

1) Grup; grup harus dibentuk, dan grup yang dibentuk harus dikelola dengan baik.

2) Akuntanbilitas; peserta didik harus bertanggung jawab terhadap kualitas kerja diri dan kelompok mereka.

3) Umpan Balik; peserta didik harus menerima umpan balik yang sering dan tepat pada waktunya sehingga dapat membuat peserta didik menjadi semakin bertanggung jawab.

4) Desain Penugasan; tugas kelompok harus mendorong pembelajaran dan pengembangan tim.

Menurut Michaelsen (Dwirahayu, Kustiawati, dan Nurmala 2018:5) team based learning memiliki 3 tahapan kegiatan pembelajaran antara lain: (1) tahap persiapan (preparation), (2) tahap kesiapan siswa (readiness assurance), dan (3) tahap implementasi atau penerapan konsep (application of course concepts). Tahapan dari pelaksanaan pembelajaran team based learning terdapat pada gambar 1 (Michaelsen dan Sweet, 2008).

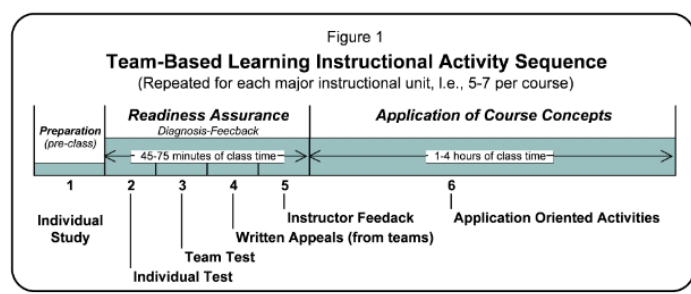

Gambar 1. Tahapan Pembelajaran Team Based Learning

Menurut Akinoglu dan Tandagon (2007) problem solving merupakan model pembelajaran berpusat pada peserta didik, membangun pembelajaran aktif yang berhubungan dengan menyelesaikan masalah, berfikir, kerja kelompok, komunikasi, menerima dan member informasi dengan peserta didik lainnya juga meningkat. Menurut Komariah (2011) problem solving memiliki tiga ciri utama yaitu: (1) merupakan rangkaian aktivitas pembelajaran yang harus dilakukan peserta didik dan menuntut peseta didik untuk aktif berpikir, berkomunikasi mencari dan mengolah data, dan menyimpulkan, (2) pembelajaran yang mengarah kepada penyelasaian masalah dimana masalah merupakan kata kunci dari proses pembelajaran dan (3) pemecahan masalah dilakukan dengan menggunakan pendekatan berpikir secara imiah yang dilakukan secara sistematis dan empiris. Menurut Heller dkk (Lestari, Maria S, dan Mahmuda, 2019) tahapan strategi penyelesaian masalah ialah: (1) visualisize the problem, (2) physics description, (3) plan a solution, (4) execute the plan, dan (5) check and evaluate.

Menurut Jubile Enterprise (Yensy, 2020:66) mendefinisikan whatsapp sebagai aplikasi chatting yang bisa mengirim pesan teks secara instan serta memungkinkan mengirim gambar, suara, dan lokasi ke orang lain dengan menggunakan smartphone jenis apapun. Menurut Hutami dan Nugraheni (2020:127) whatsapp mempunyai banyak fungsi yang dapat dimanfaatkan seperti mengirim pesan, chat grup, berbagi foto, video, voice note, dan dokumen.

Menurut Wibawanto (Monica dan Fitriawati, 2020) zoom cloud meeting merupakan aplikasi yang digunakan sebagai media komunikasi jarak jauh dengan menggabungkan konferensi video, obrolan, pertemuan online dan kolaborasi seluler. Dengan adanya fitur-fitur yang ada pada aplikasi zoom penggunaan aplikasi tersebut dapat memaksimalkan oleh para pengajar dalam proses pembelajaran (Setiani, 2020).

Pada masa pasca pandemi saat ini pemerintah banyak menerapkan kebijakan- 
kebijakan bertujuan meminimalisir angka peningkatan Covid-19. Salah satu kebijakan yang diterapkan pemerintah yaitu sistem pembelajaran jarak jauh (PJJ). Sistem ini diterapkan guna proses pembelajaran dapat tetap berlangsung walaupun dalam kondisi pandemi maupun pasca pandemi. Pembelajaran jarak jauh dapat dilakukan dengan dua cara yaitu pembelajaran dalam jaringan dan pembelajaran luar jaring. Sekolahsekolah di Indonesia pada umumnya menerapkan sistem pembelajaran jarak jauh dengan cara pembelajaran dalam jaringan dengan maksud menghindari kerumunan. Agar pembelajaran dalam jaringan dapat berlangsung diperlukan media yang mendukung proses belajar mengajar seperti laptop, jaringan data seluler, dan gawai (smartphone). Adapun media pendukung lainnya yaitu pemanfaatan aplikasi dalam proses pembelajaran seperti, Google classroom, Google meet, Whatsapp, Zoom meeting, dan masih banyak lagi.

Pembelajaran dalam jaringan yang dilaksanakan melalui media perantara menimbulkan beberapa dampak yang dapat dirasakan oleh berbagai pihak baik guru, peserta didik, hingga orang tua. Dampak yang ditimbulkan seperti menurunnya motivasi dan minat peserta didik dalam mengikuti proses belajar mengajar dalam jaringan yang diakibatkan oleh terbatasnya pelaksanaan pembelajaran sehingga kurangnya interaksi antara guru dan peserta didik. Mengacu pada permasalahan tersebut pembelajaran daring pada saat ini memerlukan inovasi agar pembelajaran lebih berkualitas. Salah satu solusi yang dapat dilakukan oleh guru yaitu berinovasi dengan mengembangkan perangkat pembelajaran yang menggunakan model, metode, dan pendekatan yang sesuai dengan kondisi saat ini.

Salah satu model yang dapat dijadikan sebagai inovasi untuk mengatasi masalah di atas adalah model pembelajaran Team Based Learning. Model ini dipilih karena dapat menjadi tantangan bagi siswa untuk berpartisipasi langsung dalam mengkonstruksi konsep. Seperti yang dikemukakan oleh Ouellette dan Blount (Islamarida 2019:13) bahwa team based learning menawarkan alternatif pada pembelajaran tradisional dan menimbulkan inovasi baru guna memfasilitasi siswa dalam berpikir kritis dan kerja sama. Sejalan dengan hal ini menurut Persky (2012:2), pembelajaran berbasis tim dapat meningkatkan profesionalisme siswa dan memberikan kesempatan untuk mengembangkan keterampilan yang diperlukan dalam dunia kerja. Serta Timmerman dan Morris (2015:280) pembelajaran team based learning hadir untuk meningkatkan pembelajaran yang aktif dan berpikir kritis peserta didik dengan melibatkan peserta didik dengan permasalahan. Penggunaan team based learning sebagai model pembelajaran memungkinkan peserta didik untuk mengembangkan pengetahuan dan keterampilan berpikir kritis, kolaborasi, kreativitass, dan komunnikasi sehingga mengarah pada peningkatan keterlibatan peserta didik dan hasil pembelajaran yang lebih baik.

Guna meningkatkan keterampilan memecahkan masalah peserta didik peneliti mengadopsi problem solving yang diimplementasikan pada lembar kerja peserta didik pada perangkat pembelajaran team based learning. Adapun tujuan dari penelitian ini yaitu untuk mengembangkan perangkat pembelajaran team based learning-problem solving berbantuan whatsapp dan zoom meeting pada pembelajaran daring yang layak dan praktis.

\section{METODE PENELITIAN}

Penelitian ini merupakan penelitian pengembangan (Research and Development) dengan menggunakan model pengembangan Plomp. Teknik pengumpulan data dari penelitian ini yaitu melalui uji validitas konstruk dan kepraktisan melalui observasi keterlaksanaan pembelajaran, kuesioner (angket) respon guru terhadap perangkat pembelajaran yang dikembangkan, dan kuesioner (angket) respon peserta didik terhadap proses pembelajaran menggunakan perangkat pembelajaran team based learning. Adapun alur rancangan pada penelitian ini ditunukkan pada Gambar 2

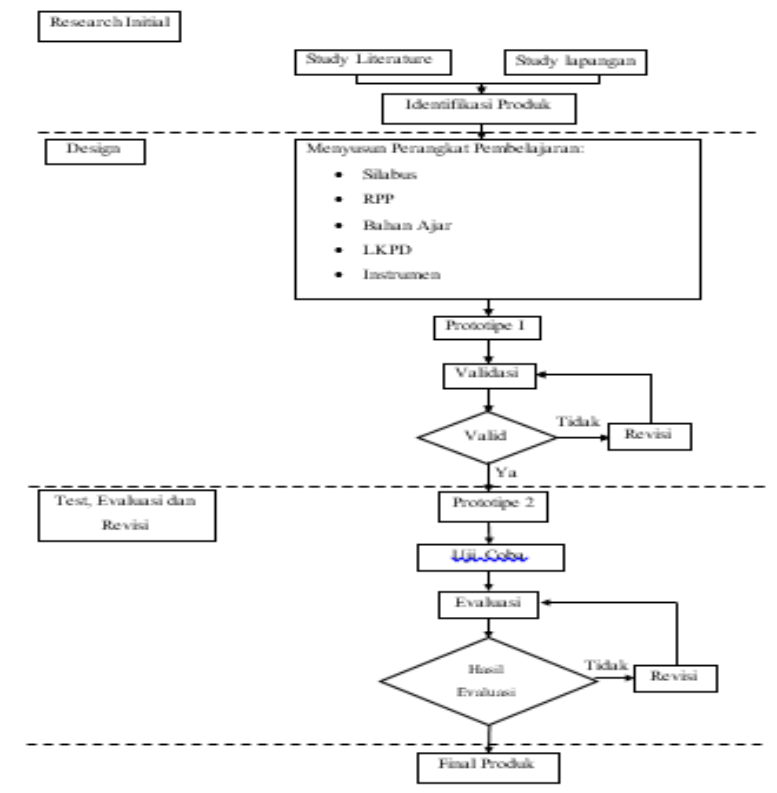

Gambar 2. Alur Rancangan Penelitian 
Teknik analisis data yang digunakan yaitu analisis deskriptif terhadap hasil validasi perangkat pembelajaran, observasi keterlaksanaan dianalisis dengan menghitung persentase keterlaksanaan, dan kuesioner (angket) respon dianalisis menggunakan Skala Likert.

\section{HASIL DAN PEMBAHASAN}

Hasil

a. Kelayakan

Kelayakan perangkat pembelajaran team based learning diuji melalui uji validitas konstruk, dimana uji validitas konstruk dilakukan oleh para ahli (validator). Adapun komponen perangkat pembelajaran yang divalidasi yakni: (1) silabus, (2) RPP, (3) LKPD, dan (4) bahan ajar. Adapun hasil validasi dari para ahli melalui uji validitas konstruk sebagai berikut.

Tabel 1. Hasil Validasi Perangkat Pembelajaran

\begin{tabular}{ccccc}
\hline \multirow{2}{*}{ Validator } & \multicolumn{4}{c}{ Persentase } \\
\cline { 2 - 5 } & Silabus & RPP & $\begin{array}{c}\text { Bahan } \\
\text { Ajar }\end{array}$ & LKPD \\
\hline I & 100 & 75.9 & 79.68 & 76.56 \\
II & 95 & 82.27 & 79.68 & 75.78 \\
III & 100 & 77.27 & 79.68 & 75.78 \\
\hline Rerata & 98.33 & 78.48 & 79.68 & 76.04 \\
\hline
\end{tabular}

Berdasarkan tabel 1. dapat dilihat bahwa rata-rata hasil validasi dari ketiga validator silabus sebesar $98,33 \%$, RPP sebesar $78,48 \%$, bahan ajar $79,68 \%$, dan LKPD sebesar $76,04 \%$ sehingga diperoleh perangkat pembelajaran yang dikembangkan valid.

b. Kepraktisan

Kepraktisan perangkat pembelajaran team based learning diukur melalui observasi keterlaksanan pembelajaran, kuesioner (angket) respon guru terhadap perangkat pembelajaran team based learning, dan kuesioner (angket) peserta didik mengenai proses pembelajaran menggunakan perangkat pembelajaran team based learning. Adapun hasil penelitian untuk kepraktisan perangkat pembelajaran diperoleh sebagai berikut.

a) Keterlaksanaan Pembelajaran

Data keterlaksanaan pembelajaran diperoleh melalui lembar observasi keterlaksanaan yang diisi oleh pengamat pada saat peneliti melakukan proses pembelajaran di sekolah. Lembar observasi keterlaksanaan berisi langkah-langkah pembelajaran pada RPP dengan melihat terlaksananya atau tidak langkah-langkah pembelajaran yang ada pada RPP. Adapun hasil pengamatan observasi keterlaksanaan pembelajaran diperoleh sebagai berikut.

Tabel 2. Persentase Keterlaksanaan Pembelajaran

\begin{tabular}{ccc}
\multicolumn{3}{c}{ Pembelajaran } \\
Pertemuan & $\begin{array}{c}\text { Persentase } \\
\text { Keterlaksanaan } \\
\text { Pembelajaran } \\
(\%)\end{array}$ & Kriteria \\
\hline I & 92.85 & Sangat Baik \\
II & 91.66 & Sangat Baik \\
III & 92.85 & Sangat Baik \\
IV & 91.66 & Sangat Baik \\
\hline Rerata & 92.26 & Sangat Baik \\
\hline
\end{tabular}

Berdasarkan tabel 2. dapat dilihat bahwa skor rata-rata keterlaksaan pembelajaran yakni sebesar $92,26 \%$ dan termasuk dalam kategori sangat baik.

b) Kuesioner (angket) respon guru

Kuesioner (angket) respon guru dalam penelitian ini digunakan untuk mengetahui respon guru terhadap perangkat pembelajaran yang dikembangkan dengan menggunakan model team based learning. Adapun hasil kuesioner (angket) respon guru sebagai berikut.

Tabel 3. Persentase Respon Guru

\begin{tabular}{cccc}
\hline Indikator & Skor & $\begin{array}{c}\text { Persentase } \\
\text { Respon } \\
\text { Guru (\%) }\end{array}$ & Kriteria \\
\hline 1 & 85 & 100 & Sangat Baik \\
2 & 200 & 100 & Sangat Baik \\
3 & 106 & 96.36 & Sangat Baik \\
4 & 70 & 100 & Sangat Baik \\
5 & 55 & 100 & Sangat Baik \\
6 & 55 & 100 & Sangat Baik \\
\hline Rerata & & 99.39 & Sangat Baik \\
\hline
\end{tabular}

Berdasarkan tabel 3. dapat dilihat bahwa skor rata-rata hasil kuesioner (angket) respon untuk keseluruhan indikator sebesar $99,39 \%$ dan termasuk dalam kategori sangat baik.

c) Kuesioner (angket) respon peserta didik Kuesioner (angket) respon peserta didik digunakan guna melihat tanggapan peserta didik mengenai proses pembelajaran dengan menggunakan perangkat pembelajaran team based learning. Adapun hasil kuesioner (angket) respon peserta didik sebagai berikut.

Tabel 4. Persentase Respon Peserta Didik Persentase

\begin{tabular}{ccc} 
Indikator & $\begin{array}{c}\text { Respon Peserta } \\
\text { Didik }(\%)\end{array}$ & Kriteria \\
\hline 1 & 79.44 & Baik \\
2 & 81.14 & Baik \\
3 & 82.29 & Baik \\
\hline
\end{tabular}




\begin{tabular}{ccc}
\hline 4 & 82.18 & Baik \\
5 & 82.41 & Baik \\
6 & 83.56 & Baik \\
7 & 87.58 & Baik \\
\hline Rerata & 82.66 & Baik \\
\hline
\end{tabular}

Berdasarkan tabel 4. dapat dilihat bahwa hasil kuesioner respon peserta didik untuk keseluruhan indikator yaitu sebesar $82,66 \%$ dan termasuk dalam kategori baik.

\section{Pembahasan}

Penelitian ini merupakan penelitian pengembangan (Research and Development) yang bertujuan untuk menghasilkan perangkat pembelajaran dengan menggunakan team based learning yang valid, praktis, dan efektif. Komponen perangkat pembelajaran yang dikembangkan yaitu silabus, RPP, LKPD, bahan ajar, instrument penilaian kompetensi, self dan peer assessment, kuesioner (angket) respon guru dan peserta didik, dan lembar observasi keterlaksanaan. Dalam mengembangkan perangkat pembelajaran ini digunakan model pengembangan Plomp yang telah dimodifikasi menjadi tiga fase the research initial, design, dan test, evaluasi and revisi. Pada tahap pertama dilakukan investigasi literature dan investigasi lapangan guna mengetahui permasalahan yang ada, dalam hal penelitian ini yaitu dampak dari pembelajaran daring bagi guru dan peserta didik. Dimana menurunnya motivasi dan minat peserta didik terhadap proses pembelajaran yang dikarenakan oleh terbatasnya kegiatan pembelajaran yang dapat dilakukan dalam pembelajaran daring. Selanjutnya dari permasalahan yang ada kemudian dilakukan identifikasi solusi atau pemecahan dari permasalahan yang ada. Dari proses pengidentifikasian inilah didapatkan untuk mengembangkan perangkat pembelajaran yang dapat digunakan untuk menjadi solusi dari permasalah pembelajaran daring. Masuk pada tahap kedua yaitu tahap design, pada tahap ini perangkat pembelajaran didesign dengan menggunakan model pembelajaran team based learning sebagai prototype 1. Perangkat pembelajaran team based learning kemudian diuji kelayakannya melalui uji validitas konstruk oleh tiga validator (para ahli). Dari validasi oleh ketiga validator didapatkan rata-rata persentase validitas silabus sebesar $98,33 \%$ dimana komponen silabus yang perlu diperbaiki yaitu indeks penilaian kompetensi dan sumber belajar. Rata-rata persentase validitas RPP sebesar 78,48\% dimana komponen RPP yang perlu diperbaiki antara lain pada kesesuaian indikator dengan kompetensi dasar, tujuan pembelajaran, dan kegiatan pembelajaran. Rata-rata persentase validitas bahan ajar sebesar 79,68\% dengan komponen bahan ajar yang perlu diperbaiki antara lain yaitu pada komponen penyusun bahan ajar, penggunaan bahasa, pendalaman materi. Rata-rata persentase validitas LKPD sebesar 76,04\% dengan komponen yang perlu diperbaiki antara lain yaitu pada memuat judul LKPD, kesesuaian tingkat kesulitan dan kerumitan tingkat tingkat perkembangan kognitif peserta didik. Setelah perangkat pembelajaran diperbaiki maka didapatkan perangkat pembelajaran sebagai prototype 2 . Selanjutnya masuk pada tahap terakhir yaitu test, evaluasi dan revisi, pada tahap ini perangkat pembelajaran yang telah direvisi (prototype 2) kemudian di uji coba di sekolah kemudian peneliti mengumpulkan informasi/data mengenai keterlaksanaan pembelajaran, kuesioner (angket) respon guru mengenai perangkat pembelajaran team based learning, dan kuesioner (angket) peserta didik mengenai proses pembelajaran menggunakan perangkat pembelajaran team based learning. Selanjutnya peneliti mengevaluasi informasi/data yang didapatkan dengan analisis keterlaksanaan dan Skala Likert. Setelah melakukan evaluasi dan analisis didapatkan rata-rata persentase keterlaksaan pembelajaran sebesar 92,26\% dengan kategori sangat baik. Kemudian rata-rata persentase kuesioner (angket) respon guru terhadap perangkat pembelajaran secara keseluruhan indikator diperoleh hasil sebesar 99,39\% dengan kategori sangat baik. Adapun kuesioner (angket) respon guru terdiri atas 6 indikator penyusunnya yakni: silabus, RPP, bahan ajar, LKPD, THB, dan lembar self assessment dan peer assessment. Serta diperoleh rata-rata persentase sebesar $82,66 \%$ untuk kuesioner (angket) respon peserta didik terhadap proses pembelajaran dengan menggunakan perangkat pembelajaran team based learning. Adapun indikator penyusun kuesioner (angket) respon peserta didik terdiri dari 7 indikator yakni: pendapat peserta didik mengenai pembelajaran berbasis tim, kesan peserta didik terhadap pembelajaran berbasis tim, perasaan peserta didik selama mengikuti pembelajaran berbasis tim, ketertarikan peserta didik menggunakan aplikasi whatsapp dan zoom meeting dalam pembelajaran daring berbasis tim, perhatian peserta didik saat diskusi secara berkelompok, hasil belajar peserta didik setelah mengikuti pembelajaran berbasis tim, dan efektivitas pengunaan LKPD. Setelah uji coba, dan evaluasi maka dihasilkan final produk perangkat pembelajaran team based learning. Berdasarkan hasil ini dapat 
dikatakan bahwa perangkat pembelajaran berbasis tim valid dan praktis untuk digunakan dalam proses pembelajaran.

\section{SIMPULAN DAN SARAN}

Pengembangan

perangkat pembelajaran team based learning-problem solving berbantuan whatsapp dan zoom meeting ini telah berhasil dilakukan. Adapun dibuktikan dengan hasil persentase uji validitas konstruk yakni pada silabus 98,33\%, RPP $78,48 \%$, bahan ajar $79,68 \%$ dan LKPD 76,04\%. Kemudian kepraktisan perangkat pembelajaran yang dibuktikan melalui persentase observasi keterlaksanaan $92,26 \%$, persentase kuesioner respon guru $99,39 \%$, dan kuesioner respon peserta didik $82,66 \%$. Sehingga perangkat pembelajaran siap digunakan dalam proses belajar mengajar karena telah layak dan praktis berdasarkan hasil pengujian.

Perangkat pembelajaran team based learning-problem solving yang telah dikembangkan mampu menjadi solusi bagi guru dalam melaksanakan pembelajaran yang interaktif guna meningkatkan penguasaan konsep dan keterampilan pemecahan masalah peserta didik.

Dibalik hasil dan ketercapaian perangkat pembelajaran ini, terdapat beberapa hal yang perlu diperhatikan lebih lanjut. Perlu diadakan penelitian lebih lanjut guna meningkatkan kualitas pembelajaran dalam pembelajaran fisika.

\section{UCAPAN TERIMAKASIH}

Ucapan terimakasih kami sampaikan kepada pihak LPPM UNG selaku pemberi dana melalui dana pembiayaan penelitian BLU FMIPA 2021.

\section{DAFTAR RUJUKAN}

Akinoglu, O., \& Tandagon, R. O. (2007). The Effects of Problem-Based Active Learning in Science Education on Students Academic Achievement, Attitude and Concept Learning. Eurasia Journal of Mathematics, Science and Technology Education, 3(1).

Dwirahayu, G., Kustiawati, D., \& Nurmala, N. (2018). Penerapan Team Based Learning (TBL) untuk Meningkatkan Pemahaman Konsep Pada Materi Statistik. Jurnal Pengajaran MIPA UPI, 23(1), 1-11.

Hobri. (2010). Metedologi Penelitian Pengembangan. Pena Salsabila.

Hutami, M. S., \& Nugraheni, A. S. (2020). Metode Pembelajaran Melalui Whatsapp Group Sebagai Antisipasi Penyebaran Covid-19 pada AUD di TK ABA Kleco Kotagede. 9(1), 126-130.
Islamarida, R. (2019). Team Based Learning ( Tbl) Dalam Peningkatan Pengetahuan , Hasil Belajar Dan Kerjasama: Literature Review. JURNAL EDUNursing, 3(1), 1218.

Komariah. (2011). Penerapan Metode Pembelajaran Problem Solving Model Polya Untuk Meningkatkan Kemampuan Memecahkan Masalah Bagi Siswa Kelas IX J di SMPN 3 Cimahi. Universitas Negeri Yogyakarta.

Lestari, K., Maria S, H. T., \& Mahmuda, D. (2019). Penerapan Penyelesaian Masalah Heller Untuk Meningkatkan Kemampuan Menyelesaikan Soal Materi Gera Lurus. Jurnal Pendidikan Dan Pembelajaran Khatulistiwa, 8(3), 2-9.

Michaelsen, L. K., \& Sweet, M. (2008). The essential elements of team-based learning. New Directions for Teaching and Learning, 116, 7-27. https://doi.org/10.1002/tt.330

Monica, J., \& Fitriawati, D. (2020). Efektivitas Penggunaan Aplikasi Zoom Sebagai Media Pembelajaran Online Pada Mahasiswa Saat Pandemi Covid-19. Jurnal Communio: Jurnal Jurusan IImu Komunikasi, 9(2), 1630-1640. https://doi.org/10.35508/jikom.v9i2.2416

Persky, A. M. (2012). The impact of team-based learning on a foundational pharmacokinetics course. American Journal of Pharmaceutical Education, 76(2), 1-10. https://doi.org/10.5688/ajpe76231

Setiani, A. (2020). Efektivitas Proses Belajar Melalui Aplikasi Zoom Di Masa Pandemi Covid-19. Academia.Edu, 2, 45-58.

Timmerman, J. E., \& Morris, R. F. (2015). Creation of Exercises for Team-Based Learning in Business. International Journal of Teaching and Learning in Higher Education Machuga \& Smith, 27(2), 280-291.

Trianto. (2008). Mendesain Pembelajaran Kontekstual Di Kelas. Cerdas Pustaka Publisher.

Vries, D. (2021). Team-based Learning: Engaging learners and creating team accountability.

Yensy, N. A. (2020). Efektifitas pembelajaran statistika matematika melalui media whatsapp group ditinjau dari hasil belajar mahasiswa (masa pandemik Covid 19). Jurnal Pendidikan Matematika Raflesia, 05(02), 65-74. 